\section{Relative efficacy of oral analgesics after third molar extraction - a 2011 update}

\author{
S. Derry, ${ }^{1}$ P. J. Wiffen ${ }^{2}$ and R. A. Moore ${ }^{3}$
}

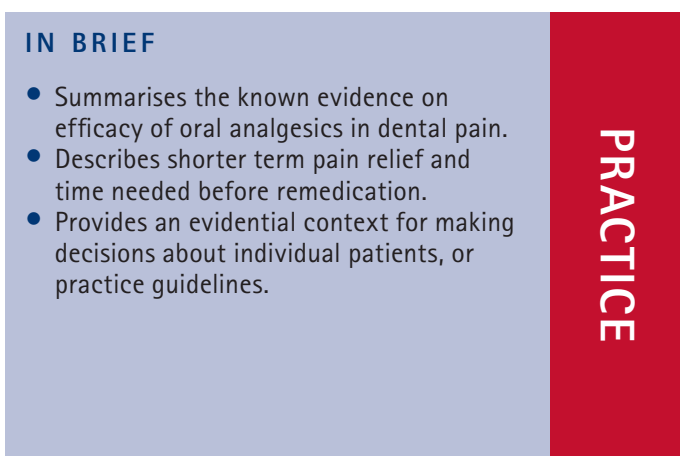

\begin{abstract}
This article provides a summary of the efficacy, and relative efficacy, of 38 different drugs or drug combinations tested in standard postoperative pain trials. It will help clinicians and patients make informed choices about analgesia based on pain relief, duration of action, and adverse events, which can then be put into context for the individual patient, depending on local availability. This article highlights the fact that no single drug is effective in all patients - even the best drugs fail to provide good levels of pain relief in at least 30\%. These patients should try a different analgesic.
\end{abstract}

In 2004 the British Dental Journal carried a review examining analgesic efficacy measured after third molar extractions, ${ }^{1}$ predominantly derived from Cochrane reviews of single dose analgesics in established moderate or severe pain. In the intervening years the reviews on which it was based have been extended to other analgesics, and updated to include relevant additional clinical trials performed in the past decade.

The culmination of this work has been the publication by the Cochrane Collaboration of an overview of these updated systematic reviews. ${ }^{2}$ The overview included 35 separate Cochrane Reviews with 38 analyses of single dose oral analgesics tested in acute postoperative pain models, with results from about 45,000 participants studied in approximately 350 individual studies. About 29,000 patients contributed data to trials in dental pain.

Each individual review reported results for dental studies where data were available, overwhelmingly in the third molar extraction pain model. Because all of the reviews used identical methods, outcomes,

$1,3^{*}$ Pain Research and Nuffield Division of Anaesthetics, Department of Clinical Neurosciences, University of Oxford, The Churchill Hospital, Oxford OX3 7LJ; ${ }^{2}$ UK Cochrane Centre, Summertown Pavilion, 18-24 Middle Way, Oxford, OX2 7LG

${ }^{*}$ Correspondence to: R. Andrew Moore

Email:andrew.moore@pru.ox.ac.uk

\section{Refereed Paper}

Accepted 12 September 2011

DOI: 10.1038/sj.bdj.2011.905

${ }^{\circledR}$ British Dental Journal 2011; 211: 419-420

Table 1 Efficacy results in dental pain studies for a range of commonly used analgesics

\begin{tabular}{|c|c|c|c|c|c|c|}
\hline \multirow[t]{2}{*}{ Drug and dose (mg) } & \multicolumn{2}{|c|}{ Number of: } & \multicolumn{2}{|c|}{$\begin{array}{l}\text { Percent with at } \\
\text { least } 50 \% \text { maxi- } \\
\text { mum pain relief }\end{array}$} & \multirow[t]{2}{*}{ NNT } & \multirow{2}{*}{$\begin{array}{l}\text { Median time to } \\
\text { remedication } \\
\text { (hr) }\end{array}$} \\
\hline & Trials & Patients & Active & Placebo & & \\
\hline Aspirin 600/650 mg & 45 & 3581 & 36 & 14 & 4.5 (4.0 to 5.2 ) & 3.0 \\
\hline Aspirin $1,000 \mathrm{mg}$ & 4 & 436 & 35 & 11 & 4.2 (3.2 to 6.0 ) & no data \\
\hline Celecoxib $400 \mathrm{mg}$ & 4 & 620 & 34 & 3 & 2.5 (2.2 to 2.9$)$ & 8.4 \\
\hline $\begin{array}{l}\text { Diclofenac } 50 \mathrm{mg} \\
\text { (Na and } \mathrm{K})\end{array}$ & 9 & 1119 & 56 & 19 & 2.7 (2.4 to 3.1$)$ & 4.3 \\
\hline Diclofenac $50 \mathrm{mg} \mathrm{K}$ & 5 & 622 & 65 & 16 & 2.1 (1.9 to 2.4$)$ & no data \\
\hline Etoriocoxib $120 \mathrm{mg}$ & 4 & 500 & 71 & 9 & 1.6 (1.5 to 1.8$)$ & $>24$ \\
\hline Ibuprofen 400 mg & 49 & 5428 & 55 & 12 & 2.3 (2.2 to 2.4$)$ & 5.6 \\
\hline $\begin{array}{l}\text { lbuprofen } 400 \mathrm{mg} \\
\text { soluble }\end{array}$ & 9 & 959 & 66 & 10 & 1.8 (1.7 to 2.0$)$ & no data \\
\hline $\begin{array}{l}\text { lbuprofen } 200 \mathrm{mg}+ \\
\text { paracetamol } 500 \mathrm{mg}\end{array}$ & 2 & 280 & 74 & 10 & $1.6(1.4$ to 1.8$)$ & $>8$ \\
\hline Naproxen 500/550 mg & 5 & 402 & 61 & 7 & $1.8(1.6$ to 2.1$)$ & 8.9 \\
\hline Paracetamol 1,000 mg & 19 & 2157 & 41 & 10 & 3.2 (2.9 to 3.6 ) & 3.9 \\
\hline
\end{tabular}

and reporting, and were all of high methodological quality, the relative efficacy of different analgesics is justifiable when established against the common comparator of placebo. ${ }^{3}$ Moreover, the methods have been extensively examined and validated using individual patient data analyses. ${ }^{4,5}$

Several approaches can be used to present results. The percentage of patients who benefit with treatment is one approach; obviously the higher the number the better. Another way is to look at the number needed to treat (NNT) for one patient to benefit; this is the treatmentspecific effect, and can be expressed as 100\%/(active\% - placebo\%). The ideal NNT is 1 , where everyone gets better with treatment and no one does with placebo; lower numbers are better. In dental trials where about $10 \%$ of patients benefit with placebo, the best possible NNT is $100 \% / 100 \%-10 \%=1.1$. 


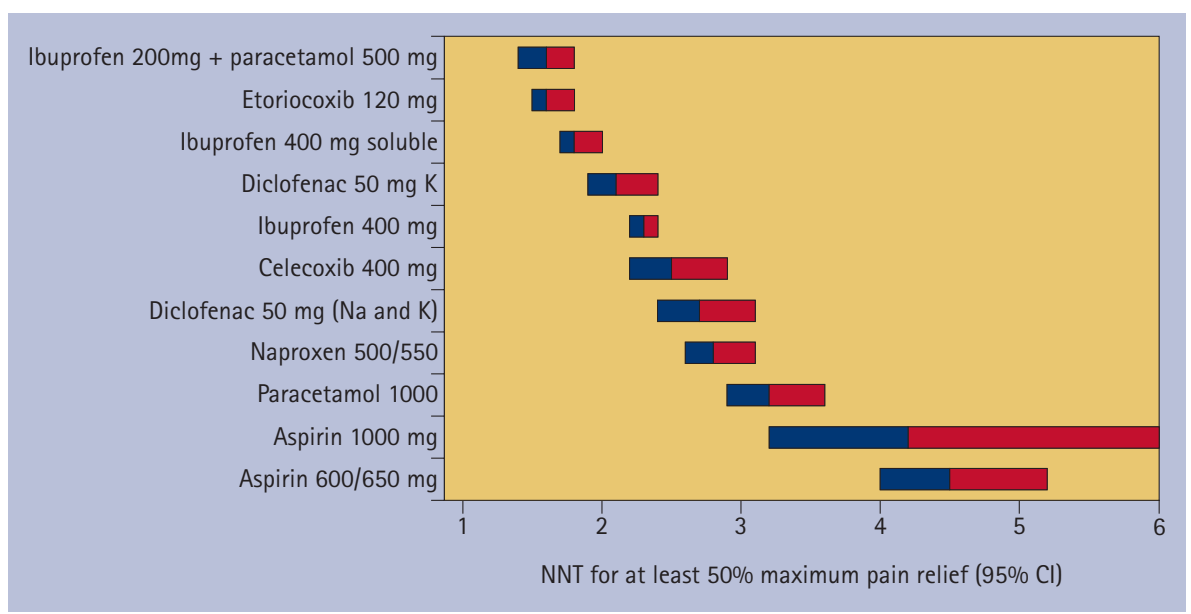

Fig. 1 NNTs in dental pain studies for a range of commonly used analgesics

This brief report describes the main results of interest to dentists, using results from the Cochrane overview and from a recent analysis of a combination of ibuprofen and paracetamol. ${ }^{5}$

\section{RESULTS}

Table 1 reports data for aspirin, celecoxib, diclofenac, etoricoxib, ibuprofen, ibuprofen plus paracetamol, naproxen, and paracetamol. Widely differing amounts of information were available for individual drugs, from as few as 402 patients for naproxen $500 / 550 \mathrm{mg}$, and as many as 5,428 for ibuprofen $400 \mathrm{mg}$.

One outcome reported is the percentage of patients with initially moderate pain (30$60 \mathrm{~mm}$ on a $100 \mathrm{~mm}$ VAS) or severe pain (more than $60 \mathrm{~mm}$ ) who obtained at least $50 \%$ of the maximum possible pain relief over a 4-6 hour period after taking the tablets. This is a high test of efficacy, achieved by only about $10 \%$ of patients who received no active treatment (placebo), but achieved by $34-74 \%$ of those who did get the active drug. Ibuprofen $200 \mathrm{mg}$ plus paracetamol $500 \mathrm{mg}$, and etoricoxib $120 \mathrm{mg}$, achieved response rates above 70\%; paracetamol $1,000 \mathrm{mg}$ achieved only a $41 \%$ response rate.

Several products had an NNT of about 2 or below: the combination of ibuprofen $200 \mathrm{mg}$ plus paracetamol $500 \mathrm{mg}$, etoricoxib $120 \mathrm{mg}$, ibuprofen $400 \mathrm{mg}$ in a soluble form, naproxen 500/550 mg, and $50 \mathrm{mg}$ of the potassium salt of diclofenac (the sodium salt being much less effective in this assay; Fig. 1).

A new outcome that some will consider relevant is the time required for half the patients to need more analgesia, the time to remedication. Longer duration is another indicator of greater effect, and for a number of analgesics median remedication times are beyond eight hours.

\section{DISCUSSION}

The 2004 review included evidence for rofecoxib and valdecoxib, neither of which is available today. New relevant information includes data on the ibuprofen plus paracetamol combination, different ibuprofen and diclofenac formulations, and etoricoxib, all of which are among the most efficacious analgesics after third molar surgery. Greater efficacy and longer duration of action tended to go together.

For one analgesic relevant to dentistry, the evidence is largely silent. For dihydrocodeine $30 \mathrm{mg}$ (still commonly used by dentists) only 136 patients were found in trials in dental pain, with only $24 \%$ obtaining at least 50\% maximum pain relief, compared with 7\% with placebo. The resultant NNT was 6 , far worse than available for drugs in Table 1, and far worse than ibuprofen $400 \mathrm{mg}$ in the only direct comparison. ${ }^{6}$ The Cochrane overview concluded that the results for dihydrocodeine were not robust because of the smallness of the data set available, and that unpublished results from just 46 patients in zero effect trials would be needed to make any result clinically irrelevant.

\section{CONCLUSION}

The amount of evidence available on single dose studies of analgesics in dental pain is large and readily available. These results are tools to help formulate policy and prescribing for individuals and populations.

1. Barden J, Edwards J E, McQuay H J, Wiffen P J, Moore $R$ A. Relative efficacy of oral analgesics after third molar extraction. Br Dent J 2004; 197: 407-411.

2. Moore R A, Derry S, McQuay H J, Wiffen P J. Single dose oral analgesics for acute postoperative pain in adults. Cochrane Database Syst Rev 2011; 9: CD008659

3. Song F, Altman D G, Glenny A M, Deeks J J. Validity of indirect comparison for estimating efficacy of competing interventions: empirical evidence from published meta-analyses. BMJ 2003; 326: 472.

4. Moore R A, Edwards J E, McQuay H J. Acute pain: individual patient meta-analysis shows the impact of different ways of analysing and presenting results. Pain 2005; 116: 322-331.

5. Moore R A, Straube S, Paine J, Derry S, McQuay H J. Minimum efficacy criteria for comparisons between treatments using individual patient metaanalysis of acute pain trials: examples of etoricoxib paracetamol, ibuprofen, and ibuprofen/paracetamo combinations after third molar extraction. Pain 2011b; 152: 982-989.

6. Moore R A, Edwards J, Derry S, McQuay H J. Single dose oral dihydrocodeine for acute postoperative pain. Cochrane Database Syst Rev 2000; 2: CD002760. 